\title{
Antiretroviral therapy adherence strategies used by patients of a large HIV clinic in Lesotho
}

\author{
Johanna Maria Axelsson ${ }^{1 *}$, Sofie Hallager ${ }^{2}$ and Toke S. Barfod ${ }^{3}$
}

\begin{abstract}
A high degree of adherence to antiretroviral therapy (ART) in patients infected with human immunodeficiency virus (HIV) is necessary for long term treatment effects. This study explores the role of timing of ART intake, the information patients received from health workers, local adherence patterns, barriers to and facilitators of ART among 28 HIV-positive adults at the Senkatana HIV Clinic in Maseru, Lesotho. This qualitative, semi-structured interview study was carried out during February and March of 2011 and responses were analyzed inspired by the Grounded Theory method. Results were then compared and discussed between the authors and the main themes that emerged were categorized. The majority of the respondents reported having missed one or more doses of medicine in the past and it was a widespread belief among patients that they were required to skip the dose of ART if they were "late". The main barriers to adherence were interruptions of daily routines or leaving the house without sufficient medicine. The use of mobile phone alarms, phone clocks and support from family and friends were major facilitators of adherence. None of the patients reported to have been counseled on family support or the use of mobile phones as helpful methods in maintaining or improving adherence to ART. Being on-time with ART was emphasized during counseling by health workers. In conclusion, patients should be advised to take the dose as soon as they remember instead of skipping the dose completely when they are late. Mobile phones and family support could be subjects to focus on during future counseling particularly with the growing numbers of mobile phones in Africa and the current focus on telemedicine.
\end{abstract}

Keywords: Adherence, Antiretroviral Therapy, Barriers, Facilitators, HIV/AIDS, Lesotho, Sub-Saharan Africa

\section{Background}

The prevalence of infections with the human immunodeficiency virus (HIV) in Lesotho among adults was estimated to be $23.1 \%$, the second highest HIV prevalence in the world, with an estimated 15,000 AIDS related deaths per year in 2012 [1]. Fifty-nine percent of eligible patients in Lesotho were estimated to receive antiretroviral therapy (ART) in 2012 [1].

The introduction of ART has changed HIV from a deadly to a chronic infection for people living with HIV (PLWH). Research has shown that there is a relationship between the level of adherence to ART and disease progression [2] and mortality [3]. Current ART can supress viral load at moderate adherence levels (70-90 \% of prescribed doses taken over a given time), to receive

\footnotetext{
* Correspondence: jm.axelsson@gmail.com

'Department of Medicine, Copenhagen University Hospital Glostrup, Glostrup, Denmark

Full list of author information is available at the end of the article
}

the best outcomes, however, ART should be taken correctly as prescribed [4].

Non-adherence increases the risk of development of resistance $[5,6]$ and since the cost of second-line therapy is considerably higher than first-line therapy, high levels of adherence is important for cost control and improved survival especially in resource-limited countries [7].

Self-reported adherence is the most widely used method to estimate adherence although it is prone to overestimate the level of adherence [8]. In a meta-analysis of 27 SubSaharan African studies conducted prior to 2006, 23 \% of the patients receiving ART had sub-optimal levels of adherence, defined by local thresholds [9]. Sub-optimal adherence is caused by different barriers to treatment adherence and frequently reported barriers in Sub-Saharan Africa include: transport costs [10-12]; lack of social support (financial and emotional) [13, 14]; service-related factors [10-14]; pill burden and side-effects [11-14]; poor knowledge about HIV; stigma [10-12]; non-disclosure of 
HIV status[10, 12, 14]; and a lack of food [12, 14]. Furthermore, adherence tend to decline over time [15-17] and a major challenge in resource poor settings is yet to provide ART to all eligible patients $[18,19]$.

To our knowledge no previous studies have been conducted exploring the information obtained during counselling on the timing of ART intake. In more affluent countries, it is suggested that HIV-positive patients are advised to take their daily ART in conjuction with daily routines, such as eating dinner or brushing their teeth [20]. However, it is our personal experience from clinical work in Lesotho and Botswana and from discussions with Sub-Saharan African colleagues that patients are often told to take their ART "on time". "On time" in this setting indicates to take the daily doses of ART at the exact same time every day. This practice may cause patients who discover that they are late, to completely skip the dose. Thus, the aims of this study was to explore adherence patterns, describe barriers to and facilitators of adherence to ART, and to investigate the role of "timing of doses" and information received at the clinic about "timing of doses".

\section{Methods}

\section{Participants, procedures and settings}

The Senkatana HIV clinic had two physicians and three nurse practitioners employed. The number of patients visiting the clinic regularly was estimated to be within the range of 6000-9000 patients. The clinic in Maseru were in 2011 one of over 30 publicly funded clinics in the city. The clinic provided counseling, ART and a few other drugs for free but not travels expenses or nutritional supplements. Prior to initiation of ART, patients were counseled by adherence counselors (nurse practitioners). Patients were given medication for one month at a time. For adherence control, patients provided their remaining medication and an adherence calendar ("mokoko") every month to the pharmacists. If patients had been non-adherent, they were told by the pharmacists to take their medicine. The pharmacists referred patients to a physician for adherence counselling if necessary. Patients were offered brief counselling during a follow-up with a physician every 3 months.

PLWH at the Senkatana HIV Clinic in Maseru, Lesotho, were purposefully selected by non-random sampling as they were awaiting their monthly clinic visit, during February and March of 2011. Patients were approached by the author, T.B., and two local research assistants. Our sampling goal was to obtain a variety among patients in terms of gender and age. Eligible patients were 18 years of age and older, HIV-positive and receiving ART. They were orally informed and gave oral consent to participation in the study. No financial compensation was given. It was emphasized that participation was entirely voluntary, all interviews were confidential and that whether the patients participated or not would not affect their treatment at the clinic. A total of 30 patients were approached for participation, however, two patients declined to participate. Both gave as reason that they wished to be financially compensated. The interview-guide consisted of 17 semi-structured questions and 14 demographic, structured questions. The author T.B. created the questionnaire based on his experience with qualitative research conducted in Denmark among PLWH and on clinical experience in low-and middle income countries. Originally written in English, the interview-guide was translated into the local language Sesotho and double checked by three independent translators. The set of questions were constructed to be comprehensive with respect to the relevant themes of adherence in an everyday setting. Each individual interview followed its own path and depended on the patient's answers. The casual form of the interviews gave the interviewer the opportunity to ask the informant to further specify certain answers. Questions regarding adherence were focused on facilitators and barriers to adherence, such as what made it difficult or easy to take the daily ART. Patients were asked about demographics including age, gender, and language, names of medicine, duration on ART, ART regimen, education and monthly household income. Patients were asked whether they had ever missed a dose of ART and how many days they had missed ART in the past month and year. Fifteen interviews were carried out by the senior author, T.B. A local translator was used in cases where the patient did not speak English. The remaining 13 interviews were carried out by two local research assistants fluent in both Sesotho and English and carefully instructed in interviewing techniques. The response to each question was written down in English during the interview, the phrasing as close to the spoken words as possible, in a slightly abbreviated form. All interviews were discussed with the author, T.B., on the same day to clarify any misunderstandings and ambiguous answers. The research protocol was approved by the Director General of Health Services in Maseru, Lesotho.

\section{Data analysis and management}

All handwritten answers were manually converted into digital forms using Microsoft Words 2010 and grouped according to specific questions in a Microsoft Excel 2010 spreadsheet by two research assistants and coauthors, J.M.A. and S.H. All digitized answers were read and approved as being identical to the original by the author T.B. The grouped responses were subsequently analyzed, inspired by the Grounded Theory method [21], by coding each answer in Microsoft Excel 2010. Results were then compared and discussed between the authors and the main themes emerging during the 
coding and analyzing process were categorized. Since this was a qualitative study and due to the small, nonrandom sample size, no statistical analyses were carried out.

\section{Results}

Demographics and ART regimen

Demographic data are presented in Table 1 and ART regimens in Table 2. Seventeen women and eleven men were interviewed. Residence was both urban settings in Maseru, and rural with up to 1 day's travelling distance to the clinic. The majority of respondents had some degree of schooling (89.3\%). A wide range in household income was seen, with a substantial part of respondents reporting dependence on a family member's income. Duration on ART varied between 2 months and 6 years with a mean of approximately 3 years, and the majority of patients were on a once daily (OD) ART regimen with one Nucleoside Analogue Reverse-Transcriptase Inhibitor (NRTI), one Nucleotide Analogue Reverse-Transcriptase Inhibitor (NtRTI) and one Non-Nucleoside Reverse-Transcriptase Inhibitor (NNRTI).

\section{Information received during counseling}

The respondents reported that they received adherence counseling when they initiated ART but no one reported explicitly having received education, counseling or advice since then. One patient reported not having received any counseling since 2004, another patient reported not having received any counseling at all and a third patient could

Table 1 Demographic data on respondents $(n=28)$

\begin{tabular}{|c|c|}
\hline Characteristics & Value \\
\hline Age, mean & 39.8 years (range $22-56$ years) \\
\hline Sex & 17 females (60.7 \%), 11 males (39.3\%) \\
\hline Years of schooling, mean & 6.96 years (10.7 \% had no education) \\
\hline $\begin{array}{l}\text { Household income per } \\
\text { month (RSA Rands) }{ }^{a}\end{array}$ & Mean: 759, Median: 600 (Range: 0-3000) \\
\hline $\begin{array}{l}\text { Number of people per } \\
\text { household }\end{array}$ & $\begin{array}{l}\text { Some are living together with their } \\
\text { siblings, parents or older relatives and } \\
\text { others have their own families with a } \\
\text { partner and typically } 1-2 \text { children. A few } \\
\text { patients lived on their own and the main } \\
\text { reason was that their partner had passed } \\
\text { away. }\end{array}$ \\
\hline $\begin{array}{l}\text { Treatment duration, } \\
\text { months }\end{array}$ & Mean: 35.9, Median: 36 (Range: 2-72) \\
\hline Type of treatment & OD: 19 (67.9 \%), BD: 9 (32.1 \%) \\
\hline $\begin{array}{l}\text { CD4-cell count (cells } / \mathrm{mm}^{3} \text { ), } \\
\text { mean }\end{array}$ & 442 (Range: 9-1300) \\
\hline
\end{tabular}

${ }^{a}$ Mean income was calculated based on the household's total reported income, regardless of whether the patient contributed or the number of individuals in the household. A few reported no income. Three participants were excluded, one because the patient had not responded to the question and two because of uncertainty about the amount of income
Table 2 ART regimen

\begin{tabular}{llll}
\hline Drugs $^{\mathrm{a}}$ & OD & $\mathrm{BD}$ & $n=28(\%)$ \\
\hline TDF, 3TC, EFV & 12 & 1 & $13(46.4)$ \\
TDF, 3TC, NVP & 1 & 4 & $5(17.9)$ \\
AZT, 3TC, EFV & & 1 & $1(3.6)$ \\
AZT, 3TC, rtv/LPV & & 1 & $1(3.6)$ \\
D4t, 3TC, EFV & & 1 & $1(3.6)$ \\
Cannot remember the name of the drug & 6 & 1 & $7(25)$ \\
Total & 19 & 9 & $28(100)$ \\
\hline
\end{tabular}

${ }^{a}$ Nucleoside analog reverse-transcriptase inhibitors (NRTIs): 3TC (Lamivudine), AZT (Zidovudine), d4T (Stavudine); Nucleotide analog reverse-transcriptase inhibitors (NtRTIs): TDF (Tenofovir); Non-nucleoside reverse-transcriptase inhibitors (NNRTIs): EFV (Efavirenz), NVP (Nevirapine); Protease inhibitors (PIs):

rtv/LPV (Ritonavir/Lopinavir)

not remember what he was counseled about because he was very ill at the time.

"I don't know because I was very ill. Cannot remember about how and when to take the medicine." 44-year old male

The message many patients recalled from their counseling was to take the medicine at the exact same time every single day, eat well and keep good hygiene, not to drink alcohol and the importance of monthly pill-refills.

"Yes, they told me that I had to take the pill at the same time and eat well and live in a clean place." 54-year old female

Patients were informed that alcohol had negative effects on adherence and health. A couple of patients mentioned being advised against traditional medicine.

"I was counseled and asked to stop taking traditional medicine because it would lower CD4 and rise viral load. Because the virus comes up I will lose weight and get other diseases." 24-year old female

Patients were recommended to use the "Mokoko" ("Mokoko" is the word for rooster in Sesotho), which is a 1-sheet, 1-month diary with symbols (e.g. a rooster for the morning, a sun for midday and a moon for evening), to help remember their doses. The patient can then check-off every time a dose has been taken on any given day. It was also used by the clinicians at the monthly clinic visits for adherence control.

"They told me to mark mokoko at same time every day. Stop beer and smoke. Stop thinking stress. Exercise every day." 49-year old male. 
It appeared that not all patients knew about their possibility to send friends or family members to refill ART at the Senkatana HIV clinic.

"We must be allowed to send other people to pick up med's. The service is slow... when picking of files [medical records]. There are three sick-leaves in a month sometime! Better if all together." 35-year old female

\section{Missed doses and the role of timing of doses}

Patients were asked what they would do if the time of correct dosing had been surpassed (Table 3). Sixteen out of $26(61.5 \%)$ patients (two patients did not respond) reported that they had missed one or more doses of medicine during their time on ART (mean time on ART: 35.5 months). Only seven patients responded to the specific questions about how many days they had missed their ART during the last month (mean: 4.7 days, range: $0-17$ ) and year (mean: 15.6 days, range: $1-72$ ).

The majority of patients had been advised by clinic staff to take the medicine either at 7 A.M. or at 7 A.M. and 7 P.M, but a few was informed to choose the time of dosage on their own.

"How and when [at the pharmacy] to take med's, choose time myself, every day, not wait with refill until finished." 36-year old male

"Stick to the chosen time and be punctual." 42-year old female

One patient explained that she had been told by a clinician to skip her daily dose, if she was more than 30 minutes late.

Table 3 Consequences of delayed doses

\begin{tabular}{|c|c|c|c|}
\hline Question & Answer & $\begin{array}{l}\text { OD } \\
(n= \\
19)\end{array}$ & $\begin{array}{l}\mathrm{BD} \\
(n= \\
9)\end{array}$ \\
\hline \multirow{9}{*}{$\begin{array}{l}\text { After how many } \\
\text { hours } \\
\text { would you skip a } \\
\text { dose } \\
\text { if you were late? }\end{array}$} & I would skip if I was 1 hour late & 1 & 2 \\
\hline & I would skip if I was 3 hours late & 2 & 1 \\
\hline & I would skip if I was 4 hours late & 4 & \\
\hline & I would skip if I was 5 hours late & 1 & \\
\hline & I would skip if I was 6 hours late & 6 & 3 \\
\hline & I would skip if I was 8 hours late & 1 & \\
\hline & $\begin{array}{l}\text { I would skip if I was } 12 \text { hours } \\
\text { late }\end{array}$ & 1 & \\
\hline & $\begin{array}{l}\text { I would take it even if } 12 \text { hours } \\
\text { late }\end{array}$ & 3 & 1 \\
\hline & $\begin{array}{l}\text { I don't know what to do if I am } \\
\text { late }\end{array}$ & & 2 \\
\hline
\end{tabular}

"Take them daily at the same hour, not after 30 minutes. Take them for the rest of life." 29-year old female

Several patients admitted that they would skip doses of ART if they came in a situation of being just a few hours late (Table 3 ) and two patients had skipped doses of ART in the past because they were late.

"I stay with my nephews and when they fight I forget to take the pills. They fight with fists. They were in the bedroom, I was in the kitchen. I keep the pills in the bedroom. I am not afraid but forget. I remember later but was told [by clinic staff] to skip [ART] if too late." 34-year old female

"Leave it, even if only 1 hour late, and ask counselor. It happened once when my wife passed away, never again." 47-year old male

\section{Barriers to adherence}

Barriers to ART-adherence reported by two or more respondents are shown in Table 4. The reason most frequently listed by the patients as a barrier to adherence was a change in routines or an unpredicted event, which could cause the patient to miss doses for various time periods, ranging from days to weeks.

"The cows were stolen and I took a week looking for them and had forgotten the medicine. 15 cows in the mountains were missing - I walked to get them." 42-year old male

"I was stressed because attackers wanted to kill my son at my home, and I forgot to pick up the medicine. I was forgetting everything even to eat for at least 3 weeks.

Table 4 Barriers to ART-adherence

\begin{tabular}{ll}
\hline Answer $^{\mathrm{a}}$ & $n=28^{\mathrm{b}}$ \\
\hline Change in routine or an unpredicted event $^{\text {Not bringing pills along when leaving the house }}$ & 10 \\
$\begin{array}{l}\text { Running out of pills or being prevented from } \\
\text { picking up refills }\end{array}$ & 6 \\
Alcohol & 4 \\
Work & 4 \\
Water and/or food were not available & 3 \\
Skipping doses of ART as told by clinic staff when \\
he/she was late
\end{tabular}

${ }^{a}$ Barriers mentioned by two respondents or more were included in the table ${ }^{\mathrm{b}}$ Respondents were allowed to mention as many options as preferred. Thus the number of response categories per person to each question could be higher than one 
Others have already been killed at night with guns, and animals are stolen." 47-year old female

Similarly, one woman said she attended a funeral, another had to take a sick child to the hospital, and a man was prevented from leaving his job because of a flood that made medicine unavailable at dose time.

The issue of not bringing pills along when leaving the house was mentioned as a reason for having missed one or more doses of medicine.

"I was in a hurry to work. The past 3 months I have been working in a factory, I get up at five and meet at seven. I carry [ART] in my pocket, but sometimes I forget to bring it along with me." 32-year old male

"I can forget it, if I am busy at work. It happens sometimes. I am a farmer, and in the morning and in evening the doses can be missed. I work 2 hours away. I bring the tablets along if I know I will be busy... but sometimes I did not know I would be busy, or I was travelling, and there was no water. I cannot take it without water." 52-year old male

"I am a driver. They can ask me to go to RSA or other countries and not sleep at home. Sometimes I could not take [ART]." 43-year old male

Another problem was running out of pills or being prevented from picking up refills. In some cases the reason for why a patient had not managed to refill in time was simply forgetfulness. Others mentioned being out of town or unable to pick up refills. In the following example the patient arrived late at the clinic and could not refill her pill bottle because the clinic was closed for the day.

"This last Friday I came after 12 [A.M.] and the reception was closed. The people were there but did not want to unlock. I was late because I had problems with the taxi. I have been told to be here at 11, but the taxi broke on the way. I missed [taking ART] Sunday through Monday and Tuesday morning." 46-year old female

Alcohol was a barrier mentioned by a few patients. One patient explained that he would skip his medicine when he had been drinking due to concerns about interactions with alcohol. Another patient missed several doses due to forgetfulness caused by alcohol.

"Yes, I was drinking beer, and was forgetting an entire week. Then I was taken to the counselor by the grandmother. It happened for only 1 week." 25-year old male
Work (meetings, long and busy working days or advice to take ART during working hours) would cause patients to postpone or miss one or more doses of ART.

"Once I postponed for three hours because I was in a meeting." 42-year old female

Another barrier to adherence was that water and/or food were not available when it was time to take the medicine. Some patients felt that the medicine made them hungry and when food was not available they would skip a dose. Another patient would not be able to swallow the pills without water.

"I was not forgetting but I defaulted because I had nothing to eat, and pills make me hungrier." 33-year old female

"I missed a dose of medicine 2 weeks ago. I was on a journey, and I had no water, but I had the tablets in my pocket." 52-year old male

Two patients reported skipping doses of ART as told by clinic staff when he/she was late with a dose. (See citations in Missed Doses and the role of Timing of Doses.)

A few reported that they missed daily doses of medicine because they simply forgot or slept over and one patient explained that the night-dose in a bi-daily (BD) ART regimen was the most difficult to remember.

\section{Facilitators of adherence}

The facilitators of ART-adherence reported by two or more respondents are shown in Table 5. A large number of respondents listed the mobile phone alarm and/or mobile phone clock as the primary tool to help remember taking ART. Not all patients had a mobile phone of their own, but most households had access to one. The mobile phone often belonged to a younger family member.

"I am reminded by my husband and by our phone alarm. The alarm rings at seven when I take it, and eight, when he takes it." 36-year old female

"My children say:" Daddy it is time to take the medicine" when they hear the phone alarm." 43-year old male

Support from family and/or friends was a frequently reported facilitator of ART-adherence.

"My sister reminds me, we live together, she is HIVunknown, but looks sick. Puts them [the pills] where I can see them." 33-year old female 
Table 5 Facilitators of ART-adherence

\begin{tabular}{ll}
\hline Answer $^{\mathrm{a}}$ & $n=28^{\mathrm{b}}$ \\
\hline Mobile phone alarm and/or mobile phone clock & 18 \\
Support from family and/or friends & 17 \\
TV and Radio & 12 \\
Regular clock or alarm clock & 9 \\
HIV-positive partner, relative or friend & 7 \\
Remember the medication pontaneously & 5 \\
Previous severe symptoms of HIV infection & 3 \\
Mokoko $^{c}$ & 2 \\
Planning ahead & 2 \\
Disclosure of HIV serostatus & 2
\end{tabular}

${ }^{\mathrm{a}}$ Facilitators mentioned by two respondents or more were included in the table ${ }^{b}$ Respondents were allowed to state/mention as many options as preferred. Thus the number of response categories per person to each question could be higher than one

"Mokoko (meaning "rooster" in Sesotho), is a markable 1-sheet 1-month calendar built up by symbols (e.g. A rooster for the morning, a sun for the day and a moon for the evening) to help patients remember their doses

"My children. They made a song called Sogum [the medicine] - "Mummy it is time for Sogum"." 45-year old female

"Wife or children [remind him] if phone battery is charged far away from home." 44-year old male

TV and radio or using a regular clock or alarm clock also played a dominant role in helping patients remember to take the medicine on time.

"Radio. I am a babysitter, listens all the time." 39-year old female

"Radio. I do not know how to read the clock." 32-year old female

"Watch, no alarm, or TV. I have no cell phone." 22-year old female

"Looks at the clock on the wall. If not home - I have another watch. Have no cell phone. Takes it after meal or if no food just takes them." 56-year old female

Another facilitator of adherence was to have an HIVpositive partner, relative or friend to share the experience with or get reminders and support from.

"My wife reminds me, she is also on ARV's, also takes them seven, but BD." 41-year old male
"My neighbor, who is also positive - asks: "now it is 7 o'clock, did you take it?"." 39-years old female

Several patients stated that they would remember their medication spontaneously. Three patients mentioned previously severe symptoms of HIV infection, which motivated them to stay adherent to ART. After initiating ART one patient began to feel better and explained:

"I have the interest in taking them [the pills] because I was very sick and got better after taking them." 47-year old female

Two patients used the mokoko to remember their daily doses of ART and two other patients were planning ahead, typically by bringing ART along when leaving the house. For example a 36-year old male always made sure he was home when it was time to take the 7 P.M. dose and he would bring ART along on travels.

Two respondents reported predominantly positive emotions and feed-back when they disclosed their HIV serostatus to family members and co-workers.

"It helps that I have disclosed to boss and all co-workers." 32-year old male

\section{Discussion}

In this qualitative study we discovered "surpassed medication intake time" as an issue, and mapped obstacles and facilitators of adherence to treatment. A change in routine, an unpredicted event or leaving home without pills was often mentioned as obstacles to ART-adherence. Use of mobile phones and social support appear to be key factors in ensuring adherence to ART.

The non-randomly selected group of adult respondents had a majority of women and an education level slightly higher than the overall estimated mean years of schooling in Lesotho, (6.9 vs. 5.9 years (2012)) [22], in congruence with the higher HIV prevalence in women [23], the slightly higher prevalence of women in Lesotho and the urbanrural disparities in school attendance [24].

The interviews indicated that the patients did not receive adherence counseling as frequently as would be optimal. It is known that adherence is not static, but is a dynamic process and tends to decline over time [15-17]. Increasing the frequency of education and counseling could therefore be an area of intervention to improve adherence in this setting, as shown in earlier Sub-Saharan studies [25].

We found that the respondents were generally told by the counselors to take their medication "on time" and unfortunately, several patients were willing to skip their medication, if they discovered they were late by just a few hours. Two patients were skipping doses of ART as told by clinic staff when he/she was late. This iatrogenic 
barrier has to our knowledge not been explored elsewhere, although it has been reported as a barrier to ART adherence by a health care provider and three patients who were failing second-line ART in a small study from RSA [26]. In more affluent countries, forgetfulness has shown to be an important barrier to ART adherence and it has been suggested to advice patients to link the daily dosage with a daily routine such as tooth brushing or having breakfast [20]. However, patients reported that inconsistency in daily routines was a primary barrier to adherence. Therefore, coupling medication intake with daily routines may be sub-optimal in this setting. There are no large randomized controlled trials which compare regimens of "on time" with "routine coupled" dosage of ART in SubSaharan Africa. In a small pilot study viral suppression was maintained at 24 and 48 weeks on intermittent treatment with an Efavirenz-based regimen (5 days on and 2 days off) [27]. In contrast, studies of longer ( $\geq 1$ week) ART interruptions have resulted in increased viral load $[28,29]$. We suggest that physicians should emphasize to patients the importance of taking a delayed dose as soon as they remember, instead of skipping the dose completely.

The main barriers to adherence in this study were related to hassles of daily life, such as a change in routine or an unpredicted event. Not bringing pills along when leaving the house was also a frequently mentioned barrier. Other researchers have reported being away from medicine at dose time as the main reasons for non-adherence [30]. Patients should be advised to maintain a travel kit filled with sufficient medication for the duration of their absence from home. Pill burden was not reported as a barrier to ART adherence in this setting but one patient found the night dose in a BD regimen as more difficult to remember than the morning dose. The majority of patients were on a OD ART regimen which could improve adherence as opposed to BD regimens [31].

A few patients had skipped doses of ART because water and/or food were not available at dose time. Lack of food [12, 14] and hunger [30, 32-34] have previously been reported as barriers to adherence to ART in sub-Saharan Africa. Cantrell et al. conducted a pilot study in Zambia, showing improved adherence with food supplements delivered to HIV patients on ART [35]. Other solutions could be to advice patients to always carry a bottle of water and a snack together with the daily ART. Alcohol is a problem in SubSaharan Africa, especially with its unfortunate effects on HIV transmission rates and ART adherence [36]. In our sample of patients, alcohol was reported as a barrier to ART adherence by four patients. The majority of patients recalled being counselled not to drink alcohol. Some patients were running out of pills or being prevented from picking up refills. At the Senkatana HIV clinic in Lesotho it is an option to send friends or family members to pick up ART at the clinic, but this was not known to all of the respondents.

In this study the mobile phone alarm and/or mobile phone clock was often used by patients or their friends and family as medication reminders. A recent qualitative study from Ethiopia report the same use of mobile phones as a reminder tool [37]. Other studies have found positive evidence with supportive text messages and other reminder devices [25, 38, 39]. At the clinic in Maseru, reminding patients by sending text messages was not an option at the time of the study. With an estimated 86.3 mobile-phone subscriptions per 100 inhabitants in Lesotho in 2013 [40] and the growing number of mobile phones in Africa [41-43], this practice could face widespread application. Most respondents had access to a mobile phone in this setting and thus, using Short Message Service in ART-clinics could be a future option. Support from family and/or friends facilitated adherence, for example the children of the person taking ART. The literature suggests school education programs for children to strengthen their role as treatment supporters [38]. Recommending patients to bring family members along to counseling and to treat family members together has shown to have a positive impact on adherence [15]. We saw a tendency to form alliances with an HIV-positive partner, relative or friend and peer-counseling has been shown to have a positive effect on adherence [44]. Several patients in this setting used the TV or radio as a reminder and other studies confirm this method's frequent use [38]. We suggest that clinicians discuss with the patient the preferred facilitators, and encourage its use.

One of the major obstacles to improvement of HIV/ AIDS health care in Sub-Saharan Africa is to ensure that all patients eligible for ART have access to ART. In 2012 an estimated $59 \%$ of all eligible patients received ART in Lesotho [1]. Once ART is initiated an estimated $72 \%$ of the patients in Lesotho are still on ART 12 months after commencement [1]. Thus retention to ART and accessibility are important issues to address. Addressing these issues may have a greater impact on survival than simply focusing on individual adherence.

To address these major challenges we suggest: introducing more flexible refill-practices, telling patients that family members are allowed to pick up medicine, introducing rations that last for more than a month, group sessions to encourage peer-support, more frequent counseling including education about disease and treatment, and sending text messages in advance to remind patients that it is time for a refill. Actions costing money like additional counseling sessions or text message services may not be realistic to implement in HIV-clinics of recourse limited countries. However, the existing counseling may be improved concerning the information given. Adherence and quality of life may be improved by allowing the patients to be more 
flexible with regard to timing of doses, for instance by taking the medicine in combination with a daily routine or to take the dose as soon as they remember instead of skipping it completely if they are delayed, and informing the patients about the potentials of mobile phones and support from family and friends. Specifically, counselors could focus on the scenario of an upcoming unexpected event or a change in routines and how to prepare patients for these situations. Finally we believe that it is of great importance that counselors are attentive towards patients' preferred methods of remembering their ART doses and try to facilitate their good behavior.

\section{Strengths and limitations}

A strength of this study is that we explored in depth the barriers and facilitators, and that the issue of "surpassed medication intake time" was discovered. The in-depth interviews in native language enhance trustworthiness of the findings. However, there are also some limitations to our study. The relatively few respondents, the fact the researchers did not speak the local language, and the lack of taped interviews. Another limitation to our study is that only patients were interviewed in depth. It would have been optimal to be able to compare patients' and clinicians' point of views. Finally, the findings of this study cannot necessarily be generalized to other countries or parts of Lesotho due to the small, non-randomly design. However, the issues of timing of doses of ART and the widespread use of mobile phones may well be useful in other Sub-Saharan African HIV clinics. This study confirms the complexity of barriers to and facilitators of adherence to ART.

\section{Conclusions}

Our findings suggest that patients are often told by clinicians to be strictly on time with their doses of ART and unfortunately several patients would skip a dose if they came in a situation of being only a few hours late. Patients should be advised to take their medicine immediately when they remember, instead of skipping it altogether when late. We hypothesize, that in some settings it may be easier for patients to be adherent to ART if the medication is linked to daily routines, for example tooth-brushing, but the literature lacks large randomized clinical trials comparing medication intake at exactly the same time each day with medication intake linked to daily routines. A major barrier to ART adherence was interruptions of daily routines and therefore coupling medication intake to daily routines may be unsuitable in this setting. Leaving the house without sufficient medicine was also listed as an important barrier and patients should be advised to maintain a travel kit. Mobile phone alarms and family support were major facilitators of adherence and is supported in the literature. None of the patients reported to have been counseled on family support or the use of mobile phones as helpful methods to improve adherence to ART. These areas could be subjects of focus during counseling particularly with the growing numbers of mobile phones in Africa and the current focus on telemedicine.

\section{Abbreviations}

ART: Antiretroviral therapy; BD: Bi-daily; HIV: Human immunodeficiency virus; NRTI: Nucleoside analog reverse-transcriptase inhibitor; NtRTI: Nucleotide analog reverse-transcriptase inhibitor; NNRTI: Non-nucleoside reverse-transcriptase inhibitor; OD: Once daily; PI: Protease inhibitor; PLWH: People living with HIV; RSA: Republic of South Africa.

\section{Competing interests}

The authors declare that they have no competing interests.

\section{Authors' contributions}

TB designed the project, created the questionnaire and led the work with conducting the interviews. JMA and SH processed the data, performed the analysis and wrote the manuscript with support from TB. All authors read and approved the final manuscript.

\section{Acknowledgements}

We would like to especially thank the study participants, the translators and the local research assistants for their contribution. Special thanks to Dr. Pearl Ntseke as the Chief Physician at the Senkatana clinic for her great support.

\section{Author details}

'Department of Medicine, Copenhagen University Hospital Glostrup, Glostrup, Denmark. ²Department of Infectious Diseases, Hvidovre University Hospital, Hvidovre, Denmark. ${ }^{3}$ Department of Medicine, Roskilde University Hospital, Roskilde, Denmark.

Received: 15 June 2015 Accepted: 23 July 2015

Published online: 06 August 2015

\section{Reference List}

1. Joint United Nations Programme on HIV/AIDS. Global Report: UNAIDS Report on the Global AIDS Epidemic 2013. Geneva: UNAIDS; 2013.

2. Bangsberg DR, Perry S, Charlebois ED, Clark RA, Roberston M, Zolopa AR, et al. Non-adherence to highly active antiretroviral therapy predicts progression to AIDS. AIDS. 2001;15(9):1181-3.

3. Wood E, Hogg RS, Yip B, Harrigan PR, O'Shaughnessy MV, Montaner JS. Effect of medication adherence on survival of HIV-infected adults who start highly active antiretroviral therapy when the CD4+ cell count is 0.200 to 0.350 x 10(9) cells/L. Ann. Intern. Med. 2003;139(10):810-6.

4. Nachega JB, Mills EJ, Schechter M. Antiretroviral therapy adherence and retention in care in middle-income and low-income countries: current status of knowledge and research priorities. Curr. Opin.HIV. AIDS. 2010;5(1):70-7.

5. Sethi AK, Celentano DD, Gange SJ, Moore RD, Gallant JE. Association between adherence to antiretroviral therapy and human immunodeficiency virus drug resistance. Clin Infect Dis. 2003;37(8):1112-8.

6. Harrigan PR, Hogg RS, Dong WW, Yip B, Wynhoven B, Woodward J, et al. Predictors of HIV drug-resistance mutations in a large antiretroviral-naive cohort initiating triple antiretroviral therapy. J Infect Dis. 2005;191(3):339-47.

7. Bennett DE, Bertagnolio S, Sutherland D, Gilks CF. The World Health Organization's global strategy for prevention and assessment of HIV drug resistance. Antivir Ther. 2008;13 Suppl 2:1-13.

8. Berg KM, Arnsten JH. Practical and conceptual challenges in measuring antiretroviral adherence. J Acquirlmmune Defic Syndr. 2006;43 Suppl 1:S79-87.

9. Mills EJ, Nachega JB, Buchan I, Orbinski J, Attaran A, Singh S, et al. Adherence to antiretroviral therapy in sub-Saharan Africa and North America: a meta-analysis. JAMA. 2006;296(6):679-90.

10. Duff P, Kipp W, Wild TC, Rubaale T, Okech-Ojony J. Barriers to accessing highly active antiretroviral therapy by HIV-positive women attending an antenatal clinic in a regional hospital in western Uganda. J Int AIDS Soc. 2010;13:37. 
11. Kip E, Ehlers VJ, van der Wal DM. Patients' adherence to anti-retroviral therapy in Botswana. J Nurs Scholarsh. 2009;41(2):149-57.

12. Murray LK, Semrau K, McCurley E, Thea DM, Scott N, Mwiya M, et al. Barriers to acceptance and adherence of antiretroviral therapy in urban Zambian women: a qualitative study. AIDS Care. 2009;21(1):78-86.

13. Dahab M, Charalambous S, Hamilton R, Fielding K, Kielmann K Churchyard GJ, et al. "That is why I stopped the ART": patients' \& providers' perspectives on barriers to and enablers of HIV treatment adherence in a South African workplace programme. BMC Public Health. 2008;8:63.

14. Sanjobo N, Frich JC, Fretheim A. Barriers and facilitators to patients' adherence to antiretroviral treatment in Zambia: a qualitative study. SAHARAJ. 2008;5(3):136-43.

15. Byakika-Tusiime J, Crane J, Oyugi JH, Ragland K, Kawuma A, Musoke P, et al. Longitudinal antiretroviral adherence in HIV+ Ugandan parents and their children initiating HAART in the MTCT-Plus family treatment model: role of depression in declining adherence over time. AIDS Behav. 2009;13 Suppl 1:82-91.

16. Liu H, Miller LG, Hays RD, Golin CE, Wu T, Wenger NS, et al. Repeated measures longitudinal analyses of HIV virologic response as a function of percent adherence, dose timing, genotypic sensitivity, and other factors. J Acquir Immune Defic Syndr. 2006;41(3):315-22.

17. Parruti G, Manzoli L, Toro PM, D'Amico G, Rotolo S, Graziani V, et al. Long-term adherence to first-line highly active antiretroviral therapy in a hospital-based cohort: predictors and impact on virologic response and relapse. AIDS Patient Care STDS. 2006;20(1):48-56.

18. Joint United Nations Programme on HIV/AIDS (UNAIDS). Global report: UNAIDS report on the global AIDS epidemic 2012. Geneva, Switzerland. 2012. http://www.unaids.org/sites/default/files/media_asset/ 20121120_UNAIDS_Global_Report_2012_with_annexes_en_1http:// www.unaids.org/sites/default/files/en/media/unaids/contentassets/ document.

19. WHO, UNICEF, UNAIDS. Global update on HIV treatment 2013: Results, impact and opportunities. Geneva, Switzerland. 2013 Jun. http:// apps.who.int/iris/bitstream/10665/85326/1/9789241505734_eng.pdf?ua=1.

20. Barfod TS, Sørensen HT, Nielsen H, Rodkjær L, Obel N. 'Simply forgot' is the most frequently stated reason for missed doses of HAART irrespective of degree of adherence. HIV Med. 2006;7(5):285-290.

21. Corbin J, Strauss A. Basics of Qualitative Research: Techniques and Procedures for Developing Grounded Theory. 3rd ed. Los Angeles: SAGE Publications; 2007.

22. United Nations Development Programme (UNDP). Human Development Report 2013 - The Rise of the South: Human Progress in a Diverse World. New York, USA. 2013. http://hdr.undp.org/sites/default/files/ reports/14/hdr2013_en_complete.pdf.

23. Ministry of Health and Social Welfare (MOHSW) [Lesotho] and ICF Macro. Lesotho Demographic and Health Survey 2009. Maseru: MOHSW and ICF Macro; 2010.

24. Liang X, Tan J-P, Mutumbuka DB. Primary and secondary education in Lesotho - a Country Status Report for education. Africa Region Human Development working paper series. Washington: World Bank; 2005.

25. Barnighausen T, Chaiyachati K, Chimbindi N, Peoples A, Haberer J, Newell ML. Interventions to increase antiretroviral adherence in sub-Saharan Africa: a systematic review of evaluation studies. Lancet Infect Dis. 2011;11(12):942-51.

26. Barnett W, Patten G, Kerschberger B, Conradie K, Garone DB, van Cutsem $G$, et al. Perceived adherence barriers among patients failing second-line antiretroviral therapy in Khayelitsha, South Africa. South Afr J HIV Med. 2013;14(2013):166-9.

27. Cohen CJ, Colson AE, Sheble-Hall AG, McLaughlin KA, Morse GD. Pilot study of a novel short-cycle antiretroviral treatment interruption strategy: 48-week results of the five-days-on, two-days-off (FOTO) study. HIV.Clin. Trials. 2007:8(1):19-23.

28. Ananworanich J, Nuesch R, Le BM, Chetchotisakd P, Vibhagool A, Wicharuk $S$, et al. Failures of 1 week on, 1 week off antiretroviral therapies in a randomized trial. AIDS. 2003;17(15):F33-7.

29. Dybul M, Nies-Kraske E, Daucher M, Hertogs K, Hallahan CW, Csako G, et al. Long-cycle structured intermittent versus continuous highly active antiretroviral therapy for the treatment of chronic infection with human immunodeficiency virus: effects on drug toxicity and on immunologic and virologic parameters. J Infect Dis. 2003;188(3):388-96.
30. Senkomago V, Guwatudde D, Breda M, Khoshnood K. Barriers to antiretroviral adherence in HIV-positive patients receiving free medication in Kayunga. Uganda AIDS Care. 2011;23(10):1246-53.

31. Parienti JJ, Bangsberg DR, Verdon R, Gardner EM. Better adherence with once-daily antiretroviral regimens: a meta-analysis. Clin Infect Dis. 2009;48(4):484-8.

32. Nagata JM, Magerenge RO, Young SL, Oguta JO, Weiser SD, Cohen CR. Social determinants, lived experiences, and consequences of household food insecurity among persons living with HIV/AIDS on the shore of Lake Victoria. Kenya AIDS Care. 2012;24(6):728-36.

33. Weiser SD, Tuller DM, Frongillo EA, Senkungu J, Mukiibi N, Bangsberg DR. Food insecurity as a barrier to sustained antiretroviral therapy adherence in Uganda. PLoS One. 2010;5(4):e10340.

34. Hardon AP, Akurut D, Comoro C, Ekezie C, Irunde HF, Gerrits T, et al. Hunger, waiting time and transport costs: time to confront challenges to ART adherence in Africa. AIDS Care. 2007;19(5):658-65.

35. Cantrell RA, Sinkala M, Megazinni K, Lawson-Marriott S, Washington S, Chi $\mathrm{BH}$, et al. A pilot study of food supplementation to improve adherence to antiretroviral therapy among food-insecure adults in Lusaka. Zambia J Acquir Immune Defic Syndr. 2008;49(2):190-5.

36. Hahn JA, Woolf-King SE, Muyindike W. Adding fuel to the fire: alcohol's effect on the HIV epidemic in Sub-Saharan Africa. CurrHIV/AIDS Rep. 2011;8(3):172-80.

37. Bezabhe WM, Chalmers L, Bereznicki LR, Peterson GM, Bimirew MA, Kassie DM. Barriers and facilitators of adherence to antiretroviral drug therapy and retention in care among adult HIV-positive patients: a qualitative study from Ethiopia. PLoS One. 2014;9(5):e97353.

38. Hardon A. World Health Organization. From access to adherence the challenges of antiretroviral treatment: studies from Botswana, Tanzania and Uganda. Geneva, Switzerland. 2006. 0 AD. http://whqlibdoc.who.int/ publications/2006/9241563281_eng.pdf

39. Horvath T, Azman H, Kennedy GE, Rutherford GW. Mobile phone text messaging for promoting adherence to antiretroviral therapy in patients with HIV infection. Cochrane Database Syst Rev. 2012;3:CD009756.

40. ITU (International Telecommunication Union). Lesotho Profile (Latest data available: 2013). http://www.itu.int/net4/itu-d/icteye/Geneva,Switzerland.

41. Africa's mobile economic revolution Killian Fox, The Guardian. 2011 Jul 24

42. Vital Wave Consulting. mHealth for Development: The Opportunity of Mobile Technology for Healthcare in the Developing World. Washington, D.C. and Berkshire, UK: UN Foundation-Vodafone Foundation Partnership. Web adress: http://www.globalproblems-globalsolutions-files.org/ unf_website/assets/publications/technology/mhealth/ mHealth_for_Development_full.pdf.

43. Africa's mobile phone industry 'booming' BBC News Africa. 2011 Nov 9.

44. Gusdal AK, Obua C, Andualem T, Wahlstrom R, Chalker J, Fochsen G. Peer counselors' role in supporting patients' adherence to ART in Ethiopia and Uganda. AIDS Care. 2011;23(6):657-62.

\section{Submit your next manuscript to BioMed Central and take full advantage of:}

- Convenient online submission

- Thorough peer review

- No space constraints or color figure charges

- Immediate publication on acceptance

- Inclusion in PubMed, CAS, Scopus and Google Scholar

- Research which is freely available for redistribution 